\title{
AGRICULTURA FAMILIAR: EFEITOS DO PRONAF NA REGIÃO OESTE DO PARANÁ
}

Fagner Mendonça Avelar ${ }^{1}$ Cristiano Stamm²

Resumo: A presente pesquisa objetivou analisar a dinâmica e os efeitos do Programa Nacional de Fortalecimento da Agricultura Familiar (PRONAF) na região Oeste do Paraná. Atualmente, as políticas direcionadas ao setor agropecuário têm dois enfoques: de um lado o fortalecimento da competitividade da agricultura empresarial, voltada para o setor externo, e de outro o fortalecimento da agricultura familiar de forma a contribuir para a geração de emprego e renda nas áreas rurais e urbanas. Para avaliar os efeitos do PRONAF utilizou-se do Modelo de dados em painel tendo em vista sua superioridade em relação à Seção-Cruzada e Séries Temporais puras. Verificou-se que o PRONAF é uma política setorial capaz de gerar efeitos positivos tanto no crescimento do produto quanto na geração de renda, emprego e receita tributária da região. Através de uma melhor orientação dos agentes envolvidos, políticas como o PRONAF, podem auxiliar no desenvolvimento de regiões com características semelhantes a estudada.

Palavras-chave: Agricultura Familiar. PRONAF. Dados em Painel.

\section{FAMILY AGRICULTURE: EFFECTS OF PRONAF IN THE WEST REGION OF PARANÁ}

Abstract: The present study aimed to analyze the dynamics and effects of the National Program for Strengthening Family Agriculture (PRONAF) in the western region of Paraná. Currently, policies directed to the agricultural sector have two approaches: on the one hand, the strengthening of the competitiveness of business agriculture, focused on the external sector, and on the other, the strengthening of family agriculture in order to contribute to the generation of employment and income in rural areas and urban areas. To evaluate the effects of PRONAF, the Panel Data Model was used in view of its superiority in relation to the Cross-Section and Pure Time Series. It was verified that the PRONAF is a sectorial policy capable of generating positive effects both in the growth of the product and in the generation of income, employment and tax revenue of the region. Through a better orientation of the agents involved, policies such as PRONAF can help in the development of regions with characteristics similar to those studied.

Keywords: Family Agriculture. PRONAF. Panel Data.

\footnotetext{
1 Universidade Estadual do Oeste do Paraná, Colegiado de Economia, Toledo, Brasil, fmavelar@hotmail.com, https://orcid.org/0000-0001-9675-7355

2 Universidade Estadual do Oeste do Paraná, Colegiado de Economia, Toledo, Brasil, stamm_br@yahoo.com.br, https://orcid.org/0000-0002-8318-9886
} 


\section{AGRICULTURA FAMILIAR: EFECTOS DEL PRONAF EN LA REGIÓN OESTE DEL PARANÁ}

Resumen: La presente investigación objetivó analizar la dinámica y los efectos del Programa Nacional de Fortalecimiento de la Agricultura Familiar (PRONAF) en la región Oeste de Paraná. Actualmente, las políticas dirigidas al sector agropecuario tienen dos enfoques: por un lado el fortalecimiento de la competitividad de la agricultura empresarial, orientada hacia el sector externo, y de otro el fortalecimiento de la agricultura familiar para contribuir a la generación de empleo y renta en las áreas rurales y urbanas. Para evaluar los efectos del PRONAF se utilizó el Modelo de datos en panel teniendo en vista su superioridad en relación a la Sección-Cruzada y las series temporales puras. Se verificó que el PRONAF es una política sectorial capaz de generar efectos positivos tanto en el crecimiento del producto como en la generación de renta, empleo e ingreso tributario de la región. A través de una mejor orientación de los agentes involucrados, políticas como el PRONAF, pueden auxiliar en el desarrollo de regiones con características similares a estudiadas.

Palabras clave: Agricultura Familiar. PRONAF. Datos en Panel.

\section{Introdução}

A importância da agricultura familiar para as economias locais é um tema crescente nas abordagens literárias sobre desenvolvimento econômico. O segmento da agricultura familiar, somente passou a ser reconhecido como importante categoria social a partir da década de 1990, logo após a promulgação da Constituição Federal do Brasil de 1988.

Os períodos anteriores à década de 1990 foram nebulosos para os pequenos agricultores brasileiros. Em grande parte isto ocorreu devido ao fato de que a rede bancaria não estava apta a atender este público. Desta forma, os recursos da política agrícola existente até então eram direcionados aos grandes produtores.

É fato esta negligência por parte do poder público em relação ao apoio a pequenos produtores rurais. Nesta época a política agrícola brasileira já era orientada para conduzir a modernização da estrutura de produção agropecuária a partir da incorporação de avanços tecnológicos. No entanto, diferentemente do que ocorre na atualidade, o público alvo englobava apenas grandes empresários rurais capitalistas.

Este cenário passou a se alterar a partir de uma maior organização dos pequenos produtores que passaram a exigir do poder público alguns direitos básicos 
essenciais para melhoria das condições produtivas no meio rural, entre eles: crédito; infraestrutura; assistência técnica; reforma agrária; educação etc.

Os movimentos sociais organizados por atores envolvidos com a agricultura familiar acabaram por pressionar o estado a olhar com outros olhos para este segmento. Estes debates contribuíram para dar maior visibilidade política a agricultura familiar enquanto segmento produtivo e de significativa importância, tanto econômica quanto social. A grande conquista destes movimentos foi a criação do Programa Nacional de Fortalecimento da Agricultura Familiar (PRONAF), em 1995.

Enquanto categoria social e produtiva, a agricultura familiar assume proporções significativas que de nenhuma forma pode ser desprezada na formulação de um projeto de desenvolvimento para o país. As dimensões deste segmento, segundo dados do último Censo Agropecuário realizado em 2006, dos mais de 5 milhões de estabelecimentos agropecuários brasileiros $84,4 \%$ pertenciam aos agricultores familiares. E estes 4.366 .267 estabelecimentos empregavam cerca de 82,8\% da População Economicamente Ativa (PEA) no setor agropecuário como um todo.

Levando em consideração as dimensões da agricultura familiar brasileira, em relação ao agronegócio nacional, e os possíveis benefícios gerados por um programa como o PRONAF, o preceito que norteou o presente estudo foi: quais os efeitos da implementação do Programa Nacional de Fortalecimento da Agricultura em regiões com forte concentração de produtores do segmento familiar?

$\mathrm{Na}$ presente pesquisa optou-se por estudar os municípios que compõem a região Oeste do Paraná. Os critérios utilizados para tal escolha levaram em consideração: a relevância da agricultura familiar para a região; e a participação da região no volume total de créditos contratados pelo estado.

Poucos foram os estudos que buscaram identificar a dinâmica e os efeitos de políticas públicas direcionadas ao segmento da agricultura familiar. Entre eles destacam-se: Silva (2008); Castro, Resende e Pires (2014).

Para identificar os efeitos do volume de créditos do programa sobre as variáveis utilizou-se os dados municipais em forma de Painel ${ }^{3}$, tendo em vista suas vantagens

\footnotetext{
${ }^{3}$ Combinação de dados de Séries Temporais com dados de Seção Cruzada (Cross-Section).
} 
em relação a dados de Seções Cruzadas ou Séries Temporais puras. Há três principais modelos para análise de dados em painel: Modelo de Mínimos Quadrados Ordinários (MQOs) empilhados, Modelo de Efeitos Fixo (EF); e Modelo de Efeitos Aleatórios (EA) (WOOLDRIDGE, 2010).

Conforme demonstrou Silva (2008), analisando os municípios do Território Médio Jequitinhonha MG, espera-se obter resultados positivos em relação ao Produto Interno Bruto - PIB (Setorial e Per Capita), ao mercado de trabalho formal, à renda média da população, à Receita Tributária Municipal e à Geração de Imposto sobre Circulação de Mercadorias e Prestação de Serviços (ICMS). O estudo mostrou a eficiência estratégica do programa em municípios compostos em grande parte por agricultores familiares.

Resultados equivalentes foram encontrados por Castro, Resende e Pires (2014). Entretanto, os autores objetivaram verificar os efeitos do programa apenas sobre o PIB Per Capita e o PIB Agropecuário em nível municipal para as cinco macrorregiões do Brasil. Já a presente pesquisa representa uma contribuição ao referido estudo, pois além de analisar um período maior (2000 a 2012), verificou-se também a influência sobre as demais variáveis econômicas, a exemplo de Silva (2008).

Este trabalho utilizou-se do modelo empírico descrito por Castro, Resende e Pires (2014), para analisar os efeitos do volume de crédito do PRONAF, nas variáveis elencadas por Silva (2008). Vale notar que não foram encontradas pesquisas com o mesmo método e com este recorte geográfico específico.

O presente trabalho está estruturado da seguinte maneira: esta introdução abordou além das características gerais da pesquisa, o problema a justificativa bem como o objetivo. A seção dois buscou caracterizar de forma histórica o surgimento do PRONAF. Em seguida a três evidenciou os dados numéricos do programa. A metodologia utilizada é tema da seção quatro. Já a seção cinco abordou os resultados da pesquisa. Por fim, a seção seis apresenta as considerações finais. 


\section{Caracterização histórica do Pronaf e suas relações com agronegócio brasileiro}

Os governos têm incentivado a agricultura brasileira ao longo dos anos de diferentes maneiras (GASQUES et al., 2004). O ano de 1965, durante o regime militar, marca a criação do Sistema Nacional de Crédito Rural (SNCR) ${ }^{4}$. Seus principais objetivos foram: i) financiar substancial parcela dos custos operacionais da produção e comercialização; ii) promover a formação de capital; iii) promover e acelerar a adoção e difusão de tecnologia moderna; e iv) fortalecer a posição econômica dos pequenos e médios agricultores.

Neste cenário a ação do Estado brasileiro orientou-se para a modernização econômica e tecnológica da grande produção, consolidando os negócios da empresa capitalista no campo com políticas de subsídio, como a de crédito agrícola (CARNEIRO, 1997).

Conforme denota Freitas e Bacha (2002), por conta da política agrícola, as culturas chamadas de exportação, como a soja e o suco de laranja, receberam maior impulso em detrimento das culturas voltadas para o mercado interno, como o arroz e a mandioca, por exemplo. Como consequência verificou-se que estas culturas tiveram crescimento de produção bem inferior ao apresentado por aquelas direcionadas a exportação.

Em março de 1995, o presidente da República anunciou a divulgação de um Programa Nacional de Fortalecimento da Agricultura Familiar. Com uma linguagem diferente da que caracterizava a postura dos governos com relação a este tema: Não se tratava de "ajudar" a "pequena produção", mas sim de concentrar os recursos escassos da política agrícola a um setor que mostrava dinamismo e viabilidade econômica, a agricultura familiar (ABRAMOVAY, 1997, p. 24).

Com vistas a "promover o desenvolvimento sustentável do segmento rural constituído pelos agricultores familiares, de modo a propiciar-Ihes o aumento da capacidade produtiva, a geração de empregos e a melhoria da renda" (BRASIL, 1996, p. 1) o PRONAF foi criado pela Resolução № 2.191 de 24/08/1995 e mais tarde instituído através do Decreto № 1.946 de 28/06/1996:

\footnotetext{
${ }^{4}$ Lei no 4.829 , de novembro de 1965.
} 
Art. 1ㅇ Instituir, no âmbito do crédito rural, o Programa Nacional de Fortalecimento da Agricultura Familiar (PRONAF), destinado ao apoio financeiro às atividades agropecuárias exploradas mediante emprego direto da força de trabalho do produtor e de sua família (BRASIL, 1996, p. 1).

Em princípio o PRONAF foi caracterizado pelas seguintes condições: para ser enquadrado como público do Programa, o agricultor não pode ter área superior a quatro módulos fiscais sob qualquer condição; tem que residir no estabelecimento ou em local próximo; obter, no mínimo, $80 \%$ da renda familiar da exploração do estabelecimento (agropecuária ou não); o trabalho familiar deve ser predominante no estabelecimento, podendo manter até dois empregados permanentes; e a renda bruta anual familiar não pode ultrapassar $\mathrm{R} \$ 30$ mil (BITTENCOURT, 2003).

Abramovay e Veiga (1999) notam que o rigoroso limite de no mínimo 80\% da renda familiar ser oriunda da atividade agropecuária teve o claro fim de evitar que agricultores patronais (médicos, advogados, entre outros profissionais liberais, etc.), que possuem áreas de até quatro módulos fiscais se beneficiassem dos recursos do programa. Verificam-se também as mesmas justificativas para limitação da renda bruta familiar de até $\mathrm{R} \$ 30 \mathrm{mil}$ por ano. Desta forma, o PRONAF iria beneficiar somente as famílias dependentes da atividade da pequena propriedade.

A aparição do PRONAF marcou um momento singular na trajetória do processo de intervenção estatal na agricultura e no setor rural Brasileiro. O PRONAF tem como objetivo fortalecer a agricultura familiar e contribuir para gerar emprego e renda nas áreas rurais e urbanas e para melhorar a qualidade de vida dos produtores familiares. De acordo com Buainain (2007) a estratégia que vem orientando as definições do estado desde a década de 1990, em relação à agricultura familiar é definida por dois componentes: o componente relacionado ao fortalecimento da competitividade da agricultura empresarial e aquele relacionado a agricultura familiar. No primeiro caso são priorizadas as questões de infraestrutura e incentivos, já no caso da agricultura familiar o fortalecimento está ligado ao PRONAF e ao Programa Nacional de Reforma Agrária. Porém, ainda de acordo com o autor, os investimentos em infraestrutura nunca foram implementados, enquanto que o PRONAF tem sido um programa de crédito de custeio. 
Do ponto de vista operacional, o PRONAF se concentra em quatro linhas de atuação:

a) financiamento da produção: o programa destina anualmente recursos para custeio e investimento, financiando atividades produtivas rurais em praticamente todos os municípios do país;

b) financiamento de infraestrutura e serviços municipais: apoio financeiro aos municípios de todas as regiões do país para a realização de obras de infraestrutura e serviços básicos;

c) capacitação e profissionalização dos agricultores familiares: promoção de cursos e treinamentos para os agricultores familiares, conselheiros municipais e equipes técnicas responsáveis pela implementação de políticas de desenvolvimento rural; e,

d) financiamento da pesquisa e extensão rural: destinação de recursos financeiros para a geração e a transferência de tecnologias para os agricultores familiares. Obviamente que esse quadro inicial da política está sendo modificado e aprimorado constantemente, visando dar maior consistência e amplitude ao programa.

Carneiro (1997) identificou certa lógica produtivista na criação do PRONAF, sustentada na tecnificação e na realização de rendimentos para o agricultor que lhe possibilite não apenas melhorar o seu padrão de vida, mas, reembolsar os investimentos públicos. É o que sugerem algumas das diretrizes que orientam as ações do Pronaf, tais como: "investir na viabilização de condições de produção e na melhoria da qualidade de vida das famílias de agricultores familiares, fortalecendo a infraestrutura física e social no meio rural; adequar o retorno dos investimentos à capacidade do pagamento dos agricultores familiares" (CARNEIRO, 1997, p. 73).

Com fins a incentivar a liberação de crédito aos agricultores familiares a resolução 2.191 tornou obrigatória a aplicação de no mínimo $20 \%$ dos recursos (MCR 6-2) 5 em financiamentos ao amparo do PRONAF. Cabe ainda notar que em um primeiro momento ficou estabelecido apenas créditos para custeio e uma taxa de 16\% a.a., bem abaixo da Taxa Selic 6 , que se situou entre 23,28\% e 21,73\% no ano de 1996. As operações contavam com rebate de adimplência de $25 \%$ sobre a referida taxa.

\footnotetext{
${ }^{5}$ Manual de Crédito Rural.

6 Define-se como a taxa média ajustada dos financiamentos diários apurados no Sistema Especial de Liquidação e de Custódia (Selic) para títulos federais (BACEN, 2015).
} 
O PRONAF começou a funcionar realmente a partir do segundo semestre de 1996, período em que a taxa de juros caiu para 9\% a.a. e foi anunciada a liberação de crédito para investimento com recursos do Fundo de Amparo ao Trabalhador (FAT). O limite dos financiamentos por beneficiário foi definido em $R \$ 5$ mil para o crédito de custeio e $\mathrm{R} \$ 15$ mil para o crédito de investimento, valores que permaneceram até o ano de 2003.

Em um primeiro momento o Ministério da Agricultura e do Abastecimento foi responsável pela gestão do programa. Em outubro de 1999, a Medida Provisória (MP) № 1.911-11 transferiu a responsabilidade para o Ministério Extraordinário de Política Fundiária. No entanto, pouco após ocorre uma reedição da MP 1.911-11 transferindo o PRONAF para Ministério da Política Fundiária e do Desenvolvimento Agrário.

Conforme levantado por Mattei (2005), o crédito direcionado para o segmento da agricultura familiar teve forte direcionamento para a área de manutenção de safras anuais e uma baixa intervenção sobre os problemas estruturais do sistema de produção. Em 1999, dos 826 mil contratos celebrados apenas 100 mil foram na modalidade investimento.

Outro fator importante neste período, foi a distribuição dos recursos pelo país. Na safra de 1999 a região Sul do Brasil deteve cerca de 60,7\% de todo o volume de recursos ao passo que a região Nordeste ficou com apenas $22 \%$ do total. Tendo em vista que a região Nordeste concentrava $50 \%$ dos estabelecimentos familiares, ficam claras algumas distorções do programa (MATTEI, 2005). A partir deste ponto, visando a melhor distribuição dos créditos, os agricultores familiares começaram a ser classificados em quatro grupos ( $A, B, C, D$ e E) em função da renda e da mão de obra utilizada.

No ano 2000 ocorreu nova queda nas taxas de juros, e estas passaram a ser fixas em $4 \%$ a.a. para custeio e de 1 a $3 \%$ a.a. para investimentos. Ressalta-se ainda a possibilidade de bônus de $25 \%$ sobre a taxa nos casos de adimplência. Este cenário de redução de taxas foi caracterizado pelo período de estabilização econômica, verificado após a implantação do Plano Real em 1994.

A partir de 2003, a exemplo do que ocorreu com as taxas dos investimentos, as taxas do custeio passaram a variar de acordo com o crédito liberado, girando de 2 
a 4\% a.a. entre 2003 e 2006. Neste período, ocorreu a criação do crédito de custeio para os assentados $(A / C)$ que já tinham recebido os recursos do PRONAF $A$ ou PROCERA. Foram iniciadas as operações do PRONAF $B$ na região Nordeste. A seguir o PROAGRO se tornou obrigatório para o crédito de custeio.

A Lei da Agricultura Familiar e dos Empreendimentos Familiares Rurais (BRASIL, 2006) - sancionada pelo presidente Lula em 24 de julho de 2006 - veio a coroar um longo e conflituoso processo de consolidação de uma política pública inovadora para o meio rural brasileiro.

Conforme verificado na presente seção, a partir da criação do PRONAF, os agricultores familiares conquistaram grandes avanços em termos de melhoria nas condições de financiamento. Contudo, vale notar que o agricultor patronal também se beneficiou deste processo, pois ao mesmo tempo em que as taxas de juros eram reduzidas para os agricultores familiares, o mesmo ocorria com as demais linhas de crédito rural.

A literatura especializada aponta diversos benefícios resultantes do PRONAF. Isto em parte era esperado, pois entre os objetivos está à geração de emprego e renda no meio rural, com uma fixação maior do homem no campo, melhorias na infraestrutura dos domicílios dos assentados e consequentes melhorias de sanidade domiciliar (CASTRO, RESENDE e PIRES, 2014).

A desregulamentação do setor agrícola nacional definiu novas relações entre as iniciativas pública e privada no sistema agroindustrial. Em termos de recursos foram desenvolvidas alternativas de crédito e garantia de renda, modificando as relações produtivas e estabelecendo uma nova base para as políticas de financiamento e comercialização das safras, mais independentes do intervencionismo e da coordenação do sistema público (BARBOSA e COUTO, 2008).

Contudo, estes instrumentos estão claramente voltados para o médio e grande produtor rural. De modo que os agricultores familiares continuam a ser beneficiados com o PRONAF, programa que demanda grande parte dos recursos destinados às políticas agrícolas brasileiras.

Se por um lado verifica-se a tendência pelo Estado de proporcionar um ambiente favorável aos agricultores, para que estes por conta própria busquem 
mecanismos de mercado para redução de seus riscos operacionais. De outro, buscase proporcionar àqueles produtores de menor renda, a margem de tais mecanismos, uma maior integração com o mercado, a fim de melhorar a qualidade de vida e reduzir os níveis de pobreza no campo. O que se observa é que para atender a estes objetivos o Estado vem se utilizando do PRONAF.

\section{PRONAF EM NÚMEROS}

O volume de recursos disponibilizados para os agricultores familiares por meio do PRONAF vem crescendo a cada ano. De acordo com os dados disponibilizados pelo MDA, a Tabela 01 apresenta a evolução do volume de crédito e o volume médio, contratados por meio do PRONAF para todo o Brasil. Nota-se um aumento significativo, cerca de $237 \%$ em 13 anos, passando de cerca de $\mathrm{R} \$ 4$ bilhões em 2000 para mais de $\mathrm{R} \$ 16$ bilhões em 2012.

O período analisado pode ser subdividido em duas principais fases, de acordo com Pires (2013): a primeira, de 2000 a 2006, observa-se que mesmo em um ambiente macroeconômico caracterizado por restrições monetárias, de crédito e fiscal com superávits fiscais primários acima dos $3,20 \%$ do PIB e controle do processo inflacionário por meio de elevadas taxas de juros reais, ocorre expansão no valor total dos contratos de empréstimos do programa, representado por cerca de $108 \%$ de variação. Este acréscimo implicou em um aumento de cerca de $172 \%$ no número de contratos. Esse valor pode ser explicado devido a política do governo Lula em garantir a concessão de créditos para os agricultores familiares financiarem suas decisões de investimentos em máquinas, equipamentos e custeio agropecuário.

Durante a segunda fase a que se refere o autor, observa-se um movimento contrário. O período coincidiu com final do primeiro e início do segundo mantado do governo Lula. Entre 2006 e 2007 ocorreu redução no volume de recursos (6,6\%) o que implicou em uma significativa redução no número de contratos da ordem de $24,6 \%$. Já nos anos de 2008 a 2012, devido à crise do Subprime ${ }^{7}$, o governo brasileiro

\footnotetext{
${ }^{7}$ Nome dado a crise originada no setor imobiliário dos Estados Unidos.
} 
adotou políticas anticíclicas a fim de amenizar o impacto da desaceleração da economia mundial. O impacto mais direto desta virada na política agrícola resultou em aumento tanto no número de contratos quanto no volume de recursos contratados.

Pires (2013) nota que entre as políticas utilizadas destaca-se a utilização do crédito como forma de ativar a demanda agregada. Desta maneira, foi disponibilizado crédito, a taxas abaixo das praticadas pelo mercado, tanto para programas sociais quanto para as atividades da agricultura familiar.

Tabela 01 - Número de contratos e volume de crédito contratados por meio do PRONAF

\begin{tabular}{c|c|c|c}
\hline Ano & $\begin{array}{c}\text { Número de } \\
\text { Contratos }\end{array}$ & $\begin{array}{c}\text { Volume de Créditos } \\
\text { PRONAF }(\mathrm{R} \$)\end{array}$ & Volume Médio (R\$) \\
\hline 2000 & 834.049 & 4.840 .618 .146 & 5.804 \\
2001 & 800.653 & 5.308 .364 .334 & 6.630 \\
2002 & 829.433 & 5.276 .162 .911 & 6.361 \\
2003 & 1.003 .837 & 6.053 .224 .924 & 6.030 \\
2004 & 1.345 .713 & 7.802 .715 .445 & 5.798 \\
2005 & 2.208 .198 & 9.568 .674 .913 & 4.333 \\
2006 & 2.551 .497 & 11.107 .253 .607 & 4.353 \\
2007 & 1.923 .317 & 10.376 .378 .449 & 5.395 \\
2008 & 1.550 .749 & 11.590 .802 .614 & 7.474 \\
2009 & 1.704 .947 & 13.973 .412 .220 & 8.196 \\
2010 & 1.585 .486 & 13.749 .732 .257 & 8.672 \\
2011 & 1.539 .901 & 14.089 .673 .911 & 9.150 \\
2012 & 1.823 .210 & 16.358 .978 .153 & 8.973 \\
\hline Total & 19.700 .990 & 130.095 .991 .883 & 6.604 \\
\hline Fonte:
\end{tabular}

Fonte: MDA, 2015.

Nota: Valores em R\$ deflacionados por meio do Deflator Implícito do PIB - Base 2012.

A Tabela 02 apresenta a evolução do volume de recursos do PRONAF para o Brasil e para cada Macrorregião geográfica. Destaca-se que durante todo o período a região Sul recebeu cerca de $48,8 \%$ de todo o volume contratado, seguido pela região Sudoeste, 21,3\%, Nordeste, 16,5\%, Norte, 6,5\% e Centro-Oeste, com 6,9\%.

Os dados mostram claras distorções entre as regiões brasileiras, visto que durante todo o período quase metade de todo o volume de crédito foi contratado na região Sul do país. A região Nordeste, onde se encontra o maior número de estabelecimentos rurais, ficou com apenas $16,5 \%$ deste volume. De acordo com Castro, Resende e Pires (2014) essa falta de proporção pode ser explicada por uma série de fatores, entre eles: 
- a maior integração dos agricultores familiares da região Sul aos mercados e a maior dependência da aquisição de insumos agrícolas para garantir a produção;

- a melhor estrutura de divulgação e operacionalização montada pela assistência técnica oficial nos estados da região Sul comparativamente às demais regiões;

- a pressão do movimento sindical junto ao governo e aos bancos;

- a existência de uma rede bancária mais bem distribuída pelos municípios em relação às demais regiões;

- a presença da assistência técnica pública na maioria dos municípios EMATERs e Empresa de Pesquisa Agropecuária e Extensão Rural de Santa Catarina (EPAGRI); e

- o surgimento do cooperativismo de crédito (CASTRO, RESENDE, \& PIRES, 2014, p. 16).

A concentração de recursos na região Sul, privilegiando uma agricultura mais estruturada e capitalizada, fez com que os agricultores mais fragilizados, que em grande parte são encontrados no Nordeste, tivessem dificuldades para obtenção de crédito, seja por não se adequarem a lógica financeira ou pelo menor nível organizacional e educacional, implicando em pouco conhecimento do funcionamento e das exigências do sistema bancário (GASQUES, et al., 2005).

Tabela 02 - Volume de recursos contratados por meio do PRONAF

\begin{tabular}{|c|c|c|c|c|c|c|}
\hline $\begin{array}{c}\text { Macrorregião } \\
\text { Ano }\end{array}$ & Norte & Nordeste & Sudeste & Sul & $\begin{array}{l}\text { Centro- } \\
\text { Oeste }\end{array}$ & Brasil \\
\hline 2000 & 309.956 .710 & 800.248 .414 & 904.471 .742 & 2.431.378.247 & 394.563 .033 & 4.840 .618 .146 \\
\hline 2001 & 339.907 .651 & 877.575 .964 & 991.870 .334 & 2.666.320.949 & 432.689 .435 & 5.308 .364 .334 \\
\hline 2002 & 337.845 .715 & 872.252 .442 & 985.853 .483 & 2.650 .146 .602 & 430.064 .669 & 5.276 .162 .911 \\
\hline 2003 & 387.602 .911 & 1.000 .715 .920 & 1.131 .047 .880 & 3.040 .454 .537 & 493.403 .676 & 6.053.224.924 \\
\hline 2004 & 499.627 .100 & 1.289 .940 .761 & 1.457 .940 .994 & 3.919 .200 .406 & 636.006 .183 & 7.802 .715 .445 \\
\hline 2005 & 515.945 .422 & 2.368.328.023 & 1.887.626.658 & 4.105.226.595 & 691.548 .215 & 9.568 .674 .913 \\
\hline 2006 & 872.218 .279 & 2.889.494.404 & 2.155 .545 .065 & 4.526.252.386 & 663.743 .472 & 11.107 .253 .607 \\
\hline 2007 & 692.456 .640 & 2.102 .460 .378 & 2.232 .162 .140 & 4.713.484.227 & 635.815 .065 & 10.376 .378 .449 \\
\hline 2008 & 540.434 .648 & 1.572 .295 .681 & 2.534.281.665 & 6.302 .187 .147 & 641.603 .474 & 11.590 .802 .614 \\
\hline 2009 & 994.096 .476 & 1.723 .281 .323 & 3.223.810.297 & 7.081 .054 .516 & 951.169 .607 & 13.973 .412 .220 \\
\hline 2010 & 977.537 .893 & 1.756 .695 .821 & 3.342.137.972 & 6.705 .781 .638 & 967.578 .934 & 13.749 .732 .257 \\
\hline 2011 & 864.031 .246 & 1.783 .401 .855 & 3.242 .881 .598 & 7.213.787.630 & 985.571 .582 & 14.089.673.911 \\
\hline 2012 & 1.186.950.218 & 2.387 .439 .699 & 3.563.929.193 & 8.174 .424 .396 & 1.046.234.647 & 16.358 .978 .153 \\
\hline Total & 8.518 .610 .910 & 21.424.130.686 & 27.653 .559 .021 & 63.529.699.275 & 8.969.991.991 & 130.095 .991 .883 \\
\hline Part. S/ Total & $6,5 \%$ & $6,5 \%$ & $21,3 \%$ & $48,8 \%$ & $6,9 \%$ & 100 \\
\hline
\end{tabular}

Fonte: MDA, 2015

Nota: Valores em R\$ deflacionados por meio do Deflator Implícito do PIB - Base 2012. 
Bittencourt e Abramovay (2001) referenciam como um dos principais fatores para estas distorções, o fato de que o público definido pelas políticas governamentais por vezes difere da clientela almejada pelos bancos. Por exigir garantias e contrapartidas para concessão de crédito, os bancos acabam por privilegiar aqueles agricultores que já fazem parte de suas carteiras de negócios.

Estas exigências por parte dos bancos excluem, no âmbito de sua atuação, parte significativa dos agricultores alvo do PRONAF, tendo em vista a existência de um real risco bancário nestas operações. Vale notar que estas exigências decorrem do fato de que os bancos respondem pelo risco dos contratos firmados, sendo assim, os mesmos redobram os cuidados a fim de evitar a inadimplência.

Decorre destes pontos a concentração dos recursos em algumas regiões, segundo Copetti (2008). Visando evitar a seletividade imposta pelo sistema bancário, o Governo Federal, remunera o sistema bancário pagando os custos administrativos de cada operação contratual, além da equalização da taxa de juros e do pagamento do Spread bancário. Esta sistemática eleva bastante o custo orçamentário do PRONAF, obrigando o Tesouro Nacional a gastar somas expressivas de recursos para garantir os compromissos deste tipo especial de política pública (COPETTI, 2008).

Esta tendência já era identificável desde os primeiros anos de implantação do programa. Abramovay e Veiga (1999) relatam que não era difícil prever que os créditos se concentrassem fundamentalmente nos estados e nos municípios em que a agricultura familiar tem maior força econômica visto que o Oeste e Sudoeste do Paraná, Oeste de Santa Catarina, Alto Uruguai, no Rio Grande do Sul, e Sul de Minas são as regiões onde mais a agricultura familiar conseguiu ligar-se a mercados dinâmicos (ABRAMOVAY \& VEIGA, 1999, p. 31).

Neste sentido, nota-se que um dos principais motivos apontados para expansão do PRONAF não está na disponibilidade de recursos financeiros, mas sim no alto custo pago pelo Tesouro Nacional para equalização dos juros, pagamento de taxas e Spread bancário. Com a adoção das regras de Basiléia e as orientações do Governo para que os bancos públicos se tornassem empresas rentáveis, fizeram com que os mesmos perdessem sua função de fomento, e suas estratégias deixaram de 
priorizar a construção da nação e o desenvolvimento econômico e social do país, restringindo-se a realização de negócios seguros e lucrativos (BITTENCOURT \& ABRAMOVAY, 2001).

Pires (2013) destaca a necessidade de repensar a estratégia de concessão de crédito do programa tendo em vista que o mesmo em vez de proporcionar o desenvolvimento dos agricultores familiares de regiões mais pobres, está claramente fortalecendo agricultores familiares que já têm acesso a mecanismos formais de mercado.

\section{Metodologia}

O modelo de dados em painel é um grande aliado na análise quantitativa de relações econômicas. Em um processo denominado pooling este modelo consegue agrupar e analisar dados de séries temporais (time series data) e dados de corte transversal (cross-section data). Conforme elencado por Gujarati e Porter (2011), existem grandes vantagens na utilização de tal modelo em relação à utilização de séries temporais ou de corte transversal, puros:

a) Combinando séries temporais com observações de corte transversal, os dados em painel oferecem dados mais informativos, maior variabilidade, menos colinearidade entre variáveis, mais graus de liberdade e mais eficiência;

b) Estudando repetidas observações em corte transversal, os dados em painel são mais adequados para examinar a dinâmica da mudança;

c) Os dados em painel podem detectar e medir melhor os efeitos que simplesmente não podem ser observados em um corte transversal puro ou em uma série temporal pura;

d) Dados em painel permitem estudar modelos de comportamento mais complicado; e

e) Ao disponibilizar os dados referentes a milhares de unidades, os dados em painel podem minimizar o viés que poderia resultar se estivéssemos trabalhando com um agregado de indivíduos ou empresas (GUJARATI \& PORTER, 2011, p. 588).

Os painéis de dados podem ser classificados de duas formas: quanto para cada indivíduo $i$ temos um número de dados temporais o painel é chamado de balanceado; por outro lado, quando não se tem a mesma quantidade de informações para cada indivíduo i, o painel é classificado como não-balanceado.

Para a formação mais simples de dados em painel, basta agrupar conjuntamente as observações de corte transversal e de série temporal disponível. 
Este modelo é conhecido na literatura como pooled regression (GUJARATI \& PORTER, 2011). Ou seja, o modelo clássico de regressão linear (MCRL):

$$
y_{i t}=\alpha_{i}+\beta X_{i t}+\varepsilon_{i t}
$$

Em que:

$\mathrm{i}=\mathrm{i}$ - ésimo indivíduo ou 1, 2,..., l;

$\mathrm{t}=\mathrm{t}$ - ésimo período ou $1,2, \ldots, \mathrm{T}$;

$y_{i t}=$ vetor com os valores da variável dependente;

$\beta=$ vetor dos parâmetros desconhecidos a serem estimados;

$X_{i t}=$ matriz com os valores das $\mathrm{k}$ variáveis independentes observáveis;

$\alpha_{i}=$ intercepto comum;

$\varepsilon_{i t}=$ erro ou perturbação do modelo;

No entanto, a regressão (1) não é recomendada para análise de dados em painel. Para tanto se faz necessário à modificação no modelo como se segue:

$$
y_{i t}=z_{i} \alpha+\beta X_{i t}+\varepsilon_{i t}
$$

A diferença entre o modelo apresentado em (2) e o anterior é o termo $z_{i}$. Este termo representa o efeito individual ou a heterogeneidade individual de cada elemento de corte transversal contendo um termo constante e um conjunto de variáveis não observadas, ou variáveis latentes tomadas constantes sobre t: a) $\varepsilon_{i t}$ é o termo de erro independente e identicamente distribuído sobre t e i, com média zero e variância $\sigma^{2}$; e, b) $\beta$ e $\alpha$ são os parâmetros a serem estimados. Greene (2002) apresentou três casos a serem considerados de acordo com a composição:

a) Se $z_{i}$ contém apenas um termo constante, o modelo de Mínimos Quadrados Ordinários (MQO) gera estimadores consistentes e eficientes para o termo comum $\alpha$ e para o vetor $\beta$ de coeficientes das variáveis exógenas. Nesse modelo, tem-se a regressão dos dados empilhados, como já citado acima no modelo (1), sem levar em consideração as características das seções cruzadas e as séries no tempo; 
b) Caso $z_{i}$ seja não observado, mas correlacionado com $X_{i t}$, isto é, ausência de exogeneidade estrita, tem-se um modelo com variável omitida e o estimador de MQO será viesado e inconsistente. Fazendo $\alpha_{i}=z_{i} \alpha$ o modelo (2) passa a ser escrito como:

$$
y_{i t}=\left(\delta+\alpha_{i}\right)+\beta X_{i t}+\varepsilon_{i t}
$$

em que $\alpha_{i}$ é uma parte do intercepto, com todos os efeitos observados nas seções, e a constante $\delta$, indica uma parcela comum a todas as seções ou no tempo. Esse modelo é conhecido como Efeito Fixo (EF), pois $\alpha_{i}$ é um termo constante em cada grupo de seção cruzada ou no tempo;

c) Caso $z_{i}$ seja não observado e não correlacionado com $X_{i t}$, ele é um componente do termo de erro e o modelo (2) pode ser reescrito como:

$$
y_{i t}=\delta+X_{i t} \beta+\left(\alpha_{i}+\varepsilon_{i t}\right)
$$

nesse caso, os estimadores são consistentes, embora ineficientes. Como $\alpha_{i}$ é um componente aleatório, o modelo é denominado de Efeito Aleatório (EA), ou seja, cada grupo de corte transversal ou série no tempo apresenta uma variável aleatória que interfere nos resultados da regressão.

Tendo em vista a disponibilidade de dados para rodar o modelo descrito a seguir, o presente trabalho compreendeu o período de 2000 a 2012. Os dados foram coletados a partir do nível municipal que conforme indica Castro, Resende e Pires (2014) é a classificação mais desagregada possível para a região Oeste do Paraná. Todos os valores monetários estão expressos em reais, a preços constantes ${ }^{8}$ de 2012.

Os dados referentes ao volume de crédito do PRONAF em escala municipal, variável explicativa (exógena) ao modelo, é disponibilizada pelo Banco Central do Brasil (BACEN). Órgão que faz o controle e fiscalização da utilização destes recursos.

Como variável endógena utilizou-se a taxa média de crescimento anual per capita do PIB Total Municipal, e de forma alternativa as taxas médias de crescimento do PIB do Agronegócio, do PIB da Indústria e do PIB do setor de Serviços. Todas disponibilizadas pelo Instituto Brasileiro de Geografia e Estatística (IBGE).

\footnotetext{
${ }^{8}$ Os dados foram corrigidos pelo deflator implícito do PIB, disponibilizado pelo IBGE.
} 
Também de forma alternativa verificou-se o impacto da variável explicativa sobre a geração de postos formais de trabalho e sobre a remuneração média dos trabalhadores, dados obtidos a partir da Relação Anual de Informações Sociais (RAIS) do Ministério do Trabalho e Emprego.

Por fim, foram verificados também impactos sobre a taxa média de crescimento anual da arrecadação líquida de impostos municipais e a taxa média de crescimento da arrecadação do Imposto Sobre a Circulação de Mercadoria e Serviços (ICMS) em termos de seus repasses aos municípios. Ambos disponibilizados pelo Instituto de Pesquisa Econômica Aplicada (IPEADATA).

As variáveis de controle utilizadas, a fim de amenizar problemas de endogeneidade conforme descrito por Temple (1999), foram: a escolaridade média dos trabalhadores, em anos de estudos, calculados a partir dos dados da RAIS; a densidade demográfica municipal; e valores no início do período para PIB Per Capita, PIB Agropecuário, PIB Indústria, PIB Serviços, Renda Média dos Trabalhadores, Arrecadação municipal líquida (Impostos) e Geração de ICMS.

Nas últimas décadas observou-se um que os modelos de dados em painel têm sido amplamente utilizados na literatura empírica do crescimento econômico (ISLAM, 1995). A motivação teórica que relaciona crescimento econômico e financiamento utilizando modelos econométricos com dados em painel pode ser facilmente encontrada em Levine (2005).

Islam (1995) mostra como os estudos empíricos de crescimento econômico moveram-se gradualmente de análises em Cross-Section para uma abordagem de dados em painel. Uma revisão bibliográfica detalhada desta linha de pesquisa pode ser encontrada em Islam (1995), Temple (1999) e Durlauf Johnson e Temple (2005).

A principal utilidade da abordagem de dados em painel é a sua capacidade de tratar o problema do viés de variável omitida, que é comum nas regressões CrossSection. Com o emprego de modelos com dados em painel é possível controlar as variáveis omitidas fixas ao longo do tempo. No entanto, os modelos de dados em painel não estão isentos de problemas, que incluem o viés de amostra pequena e a curta frequência com que os dados são utilizados (ISLAM, 1995). 
As especificações utilizadas nesta investigação que objetivou avaliar os resultados do volume de crédito do PRONAF sobre o crescimento econômico regional são os modelos tradicionais de dados em painel, conforme especificado por Durlauf Johnson e Temple (2005), em que as taxas de crescimento do PIB per capita são regredidas contra a variável de interesse (PRONAF) e algumas variáveis de controle (escolaridade média da população, densidade populacional, etc.).

Como visto o interesse desta investigação é avaliar qual o efeito da variável exógena, volume de créditos do PRONAF, sob as seguintes variáveis endógenas: PIB Total per capita, PIB agropecuário, PIB da indústria, PIB do setor de serviços, Renda média da população, Geração anual de empregos formais, Geração Impostos Líquidos Municipais e Geração de ICMS.

Na presente investigação tanto a variável endógena quanto a variável exógena são apresentadas em termos de suas taxas anuais médias de crescimento ao longo de treze anos, entre 2000 e 2012. Desta forma, o resultado obtido demonstrará em termos percentuais quais foram os efeitos do programa sobre cada uma das variáveis de interesse.

Como observado por Temple (1999), para atenuarem os problemas de endogeneidade, os pesquisadores muitas vezes fazem uso dos valores no início do período. Seguindo tal indicação utilizou-se como variáveis de controle as variáveis condicionais dadas em termos de seus valores no início de cada ano.

Três métodos alternativos para estimar os modelos de dados em painel são utilizados em escala regional. Primeiro, o modelo de mínimos quadrados ordinários (MQOs) empilhados supõe que não há nenhuma variável omitida correlacionada com as variáveis incluídas. O seguinte modelo é estimado através da especificação de MQOs empilhados (Pooled OLS):

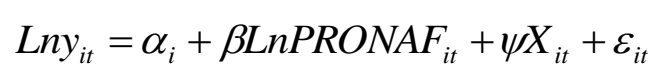

em que: $L_{n y} y_{i t}$ representa um vetor com as observações das taxas anuais médias das variáveis dependentes de cada unidade espacial $i$ entre $t$ e $t+n$. Já o vetor $L n P R O N A F_{i t}$ representa as taxas de crescimento anuais médias do volume de crédito do PRONAF. 
Além disso, a matriz $X_{i t}$ inclui as seguintes variáveis de controle: PIB Total Per Capita, PIB Agropecuário, PIB Indústria, PIB Serviços, Vínculos de Emprego Ativos, Geração de ICMS, Geração Impostos Líquidos Municipais, Renda média, densidade demográfica e nível de escolaridade média dos trabalhadores, todas em temo de seus valores no início do período conforme orienta Temple (1999).

De acordo com Islam (1995) a principal motivação para o uso da abordagem de dados em painel tem sido a possibilidade de incluir diferenças estruturais fixas no tempo entre regiões. Com este objetivo, o modelo de dados de painel com efeitos fixos $^{9}$ é estimado por meio da seguinte regressão:

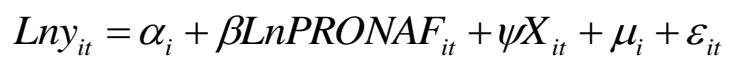

Nesta formulação, $\mu_{i}$ é incluído e representa os efeitos fixos. Esta especificação permite diferenças entre cada unidade espacial na forma de um efeito fixo individual, que é um avanço em relação às regressões cross-section e às regressões de MQOs empilhados. Islam (1995) argumenta que o modelo representado pela equação (6) torna possível incluir tanto os fatores tangíveis quanto os intangíveis, por exemplo, as características institucionais, que podem ser representadas pelo respectivo efeito fixo individual. Dessa forma, por meio da estimação da equação (6) obtém-se o coeficiente da variável PRONAF, $\beta$, que indica o impacto médio em termos percentuais do volume de crédito do PRONAF sobre cada variável de interesse.

O terceiro modelo utilizado é o modelo de efeitos aleatórios:

$$
\text { Lny }_{i t}=\alpha_{i}+\beta \operatorname{LnPRONAF_{it}}+\psi X_{i t}+\left(\delta_{i}+\varepsilon_{i t}\right)
$$

Este modelo é derivado da equação (5). A diferença entre os dois é a inserção de um termo aleatório $\delta_{i}$. Este modelo pressupõe que não há correlação entre as variáveis explicativas e o termo de erro $\varepsilon_{i t}$. Além do mais, o modelo EA considera o efeito da heterogeneidade apenas entre os municípios (cross-sections) da região, mantendo essa heterogeneidade, por suposição, constante ao longo do tempo.

Da mesma forma que a equação (2) o interesse ao estimar a equação (3) é o termo $\beta$, que demonstrará qual o impacto médio em termos percentuais do volume de crédito do PRONAF sobre cada variável de dependente.

\footnotetext{
${ }^{9}$ Especificações descritas em Greene (2002) e Wooldridge (2010).
} 
Como forma de corrigir problemas de heterocedasticidade e autocorrelação e obter erros padrões robustos, todas as regressões foram realizadas utilizando-se o método de covariância do coeficiente (coef covariance method) White Cross-Section. Para a presente pesquisa optou-se por utilizar o software Eviews em sua versão 8.1.

Por fim, vale lembrar que a escolha entre qual o melhor modelo para explicar a série de dados escolhida, ficou a cargo do teste de Hausman. Entretanto, para fins de comparação, são apresentados os resultados dos três modelos.

\section{Resultados e Discussão}

Tendo em vista a disponibilidade de dados para todas as séries no período em análise o painel utilizado foi classificado como balanceado (equilibrado). Inicialmente, foram efetuados testes de raiz unitária, a fim de identificar problemas de estacionariedade nas séries em análise. A Tabela 03 apresenta o P-Valor em nível e em 1를 diferença para os testes de Levin, Lin e Chu e Im, Pesaran e Shin.

Tabela 03 - Teste de raiz unitária para variáveis em análise.

\begin{tabular}{|c|c|c|c|c|c|c|c|c|}
\hline \multirow[t]{2}{*}{ Variáveis } & \multicolumn{2}{|c|}{$\begin{array}{l}\text { Levin, Lin e Chu } \\
\text { Nível }\end{array}$} & \multicolumn{2}{|c|}{$\begin{array}{l}\text { Levin, Lin e Chu } \\
\text { 1르 Diferença }^{\text {a }}\end{array}$} & \multicolumn{2}{|c|}{$\begin{array}{c}\text { Im, Pesaran e Shin } \\
\text { Nível }\end{array}$} & \multicolumn{2}{|c|}{$\begin{array}{l}\text { Im, Pesaran e } \\
\text { Shin } \\
\text { 1a Diferença }\end{array}$} \\
\hline & Statistic & P-Valor & Statistic & P-Valor & Statistic & P-Valor & Statistic & P-Valor \\
\hline Tx. Cresc. PRON & 1,283 & 0,900 & $-34,460$ & 0 & 4,947 & 1,000 & $-23,428$ &, 000 \\
\hline Tx. Cresc. PIB P.Cap. & $-21,838$ & 0,000 & $-21,501$ & 0,000 & $-10,360$ & 0,000 & $-14,653$ & 0,000 \\
\hline Tx. Cresc. PIB Agro. & $-21,845$ & 0,000 & $-29,390$ & 0,000 & $-12,963$ & 0,000 & $-16,515$ & 0,000 \\
\hline Tx. Cresc. PIB Ind. & $-2,699$ & 0,004 & $-24,269$ & 0,000 & 2,577 & 0,995 & $-18,322$ & 0,000 \\
\hline Tx. Cresc. PIB Serv. & $-3,732$ & 0,000 & $-30,910$ & 0,000 & 3,627 & 1,000 & $-20,891$ & 0,000 \\
\hline Tx. Cresc. Renda & $-9,479$ & 0,000 & $-29,530$ & 0,000 & $-5,997$ & 0,000 & $-19,157$ & 0,000 \\
\hline Tx. Cresc. Emprego & $-4,849$ & 0,000 & $-23,909$ & 0,000 & 2,832 & 0,998 & $-17,990$ & 0,000 \\
\hline Tx. Cresc. Rec. Imp. & $-8,608$ & 0,000 & $-21,395$ & 0,000 & $-4,829$ & 0,000 & $-14,235$ & 0,000 \\
\hline Tx. Cresc. Rec. ICMS & $-7,247$ & 0,000 & $-21,496$ & 0,000 & 0,397 & 0,654 & $-13,766$ & 0,000 \\
\hline
\end{tabular}

Fonte: Elaboração dos Autores.

Obs. Seleção de lags segundo critério de Schwarz; Teste com intercepto e sem tendência.

A partir dos dados da Tabela 03 foi possível identificar que a maioria das séries são estacionárias em nível. No entanto, a principal variável em análise, taxa de crescimento do PRONAF, possui uma raiz unitária em ambos os testes, e tendo em vista que todas as séries são estacionarias em primeira diferença, optou-se por utilizar 
todos os dados com um período de defasagem. Tal procedimento manteve o painel balanceado.

As subseções a seguir analisaram os resultados primeiramente sobre 0 crescimento econômico da região, em seguida sobre a geração de emprego e renda e por fim sobre a geração de receita tributária (Impostos Líquidos e ICMS).

\section{Efeitos do Pronaf sobre o crescimento do produto}

A Tabela 04 apresenta os resultados estimados para variáveis de interesse no presente estudo, obtidos a partir dos três modelos: MQOs para dados empilhados (Coluna 01); Painel de Efeitos Fixos (EF) (Coluna 02); e Painel de Efeitos Aleatórios (EA) (Coluna 03). Constam também os resultados do teste de Hausman para os modelos de EF e de EA, bem como a estatística t para cada coeficiente.

Foi possível verificar que o modelo de EF se adequou melhor as séries em análise. A maior vantagem do modelo de EF é a possibilidade de minimizar problemas com variáveis omitidas, o que permite analisar com maior confiança e robustez os efeitos do PRONAF sobre o crescimento econômico da região (ISLAM, 1995).

Foram analisados o desempenho do PRONAF sobre: o PIB Per Capita, o PIB Agropecuário; o PIB da Indústria; e o PIB do Setor de Serviços. Este procedimento, de acordo com Silva (2008), permitiu analisar os efeitos Inter Setoriais do programa.

Os resultados encontrados para a principal variável em estudo, Taxa de crescimento do PRONAF, são consonantes aos resultados obtidos por Castro Resende e Pires (2014). Foram obtidos resultados estatisticamente significativos nos três modelos e para as quatro variáveis de interesse. Os reflexos mensurados sugerem que o financiamento à Agricultura Familiar, realizado por intermédio do PRONAF, tem reflexo em todos os setores da economia local.

Antes de analisar especificamente cada coeficiente estimado pelo modelo de EF, melhor modelo segundo teste de Hausman, vale destacar que apesar de observarmos diferentes proporções nos três modelos, todos apresentaram impactos positivos da taxa de crescimento do PRONAF sobre as variáveis de interesse. É clara a existência de uma relação positiva entre o volume de créditos do programa e um o 
crescimento econômico da região Oeste do Paraná. Este fato está de acordo com as constatações de autores como Abramovay (1997), e Mattei (2005).

Tabela 04 - Efeitos do PRONAF sobre o crescimento do produto - região Oeste do Paraná

\begin{tabular}{|c|c|c|c|}
\hline Variáveis Explicativas & $\begin{array}{c}\text { MQOs } \\
\text { Empilhados } \\
\text { (1) }\end{array}$ & $\begin{array}{c}\text { Painel de } \\
\text { Efeitos Fixos } \\
(2)\end{array}$ & $\begin{array}{c}\text { Painel de } \\
\text { Efeitos Variáveis } \\
\text { (3) }\end{array}$ \\
\hline \multirow{3}{*}{ Tx. Cresc. Créditos do PRONAF } & \multicolumn{3}{|c|}{ Variável Dependente: PIB Total Per Capita } \\
\hline & $0,0277^{\star * *}$ & \multirow{2}{*}{$0,0343^{* * *}$} & \multirow{2}{*}{$\begin{array}{r}0,0318^{\star * *} \\
(6,08)\end{array}$} \\
\hline & \multirow{3}{*}{$\begin{array}{r}(4,96) \\
0,8790\end{array}$} & & \\
\hline $\mathrm{R}^{2}$ Ajustado & & 0,9004 & 0,8876 \\
\hline Teste Hausman & & \multicolumn{2}{|c|}{$33,65[0,0000]$} \\
\hline \multirow[b]{2}{*}{ Tx. Cresc. Créditos do PRONAF } & \multicolumn{3}{|c|}{ Variável Dependente: PIB Agropecuário } \\
\hline & $\begin{array}{r}0,1376^{* * *} \\
(8.93)\end{array}$ & $0,1772^{* * *}$ & $0,1376^{* * *}$ \\
\hline \multirow{2}{*}{$\begin{array}{l}\mathrm{R}^{2} \text { Ajustado } \\
\text { Teste Hausman }\end{array}$} & \multirow[t]{2}{*}{$\begin{array}{r}(8,93) \\
0,8368\end{array}$} & $\begin{array}{l}(10,82) \\
0,8531\end{array}$ & $\begin{array}{r}(9,33) \\
0,8368\end{array}$ \\
\hline & & \multicolumn{2}{|c|}{$55,34[0,0000]$} \\
\hline & \multicolumn{3}{|c|}{ Variável Dependente: PIB da Indústria } \\
\hline \multirow[t]{2}{*}{ Tx. Cresc. Créditos do PRONAF } & $0,7755^{* * *}$ & $0,7980^{* * *}$ & $0,7755^{* * *}$ \\
\hline & \multirow[t]{2}{*}{$\begin{array}{l}(18,89) \\
0,7426\end{array}$} & 0,7534 & $\begin{array}{l}(19,12) \\
0,7426 \\
\end{array}$ \\
\hline $\begin{array}{l}\mathrm{R}^{2} \text { Ajustado } \\
\text { Teste Hausman }\end{array}$ & & \multicolumn{2}{|c|}{$21,73[0,0006]$} \\
\hline \multirow{3}{*}{ Tx. Cresc. Créditos do PRONAF } & \multicolumn{3}{|c|}{ Variável Dependente: PIB Setor de Serviços } \\
\hline & $0,4358^{\star * *}$ & $0,4619^{* * *}$ & $0,4358^{\star \star *}$ \\
\hline & \multirow{2}{*}{0,79} & $\begin{array}{r}(19,54) \\
08050\end{array}$ & $\begin{array}{l}(19,35 \\
0797\end{array}$ \\
\hline \multirow{2}{*}{$\begin{array}{l}\mathrm{R}^{2} \text { Ajustado } \\
\text { Teste Hausman } \\
\text { Observacões }\end{array}$} & & \multicolumn{2}{|c|}{$20,05 \quad[0,0012]$} \\
\hline & 600 & 600 & 60 \\
\hline
\end{tabular}

Fonte: Elaboração dos autores.

( ) = T-Statistic, [ ] = P-valor.

${ }^{* \star \star}$ Significativo a $1 \%$; ${ }^{* \star}$ Significativo a $5 \%$; ${ }^{*}$ Significativo a $10 \%$.

O modelo de EF apresentou um coeficiente da Taxa de crescimento do PRONAF em relação ao crescimento anual do PIB Per Capita de 0,0343, estatisticamente significativo a 1\%. Este resultado indica que a cada 10 pontos percentuais (p.p.) de aumento na taxa de crescimento do volume de créditos do PRONAF ocorre em média um acréscimo de $0,34 \%$ de crescimento anual no PIB Per Capita da região. Este resultado por si só já demonstra a importância do programa para a produção agregada do Oeste paranaense.

Ao se avaliar o desempenho sobre o PIB Agropecuário obteve-se valores de maior magnitude em comparação ao PIB Per Capita. O coeficiente estimado pelo modelo de EF foi de 0,1772, com um nível de $1 \%$ de significância podendo-se dizer 
que acréscimos de 10 p.p. na taxa de crescimento anual do volume de créditos do PRONAF ocasionarão acréscimos em média de $1,77 \%$ no crescimento anual do PIB Agropecuário.

Em termos gerais cabe mencionar que por ser uma política de incentivo ao setor agropecuário (setor primário), o agricultor familiar passa a fornecer insumos tanto para o setor de serviços quanto para o setor industrial. Os coeficientes estimados destacam as relações Inter Setoriais que o programa proporciona, conforme mencionado por Silva (2008).

Em relação à taxa de crescimento do PIB da indústria o coeficiente estimado, pelo modelo de EF, foi de 0,7980 , também com $1 \%$ de significância. Acréscimos de 10 p.p. na taxa de crescimento do volume de créditos do PRONAF ocasionam acréscimos de 7,98\% no crescimento anual do PIB da Indústria da região Oeste do Paraná.

Ao considerar o desempenho sobre o PIB do setor de Serviços, assim como os demais, verificou-se também uma relação positiva entre as variáveis. O coeficiente estimado foi de 0,4619 , significando um acréscimo de $4,62 \%$ no crescimento anual do PIB do setor de Serviços em resposta a um acréscimo de 10 p.p. na taxa de crescimento anual do volume de créditos do PRONAF.

Nota-se que os efeitos sobre o produto dos setores de serviços e da indústria é ainda maior que o observado para o setor agropecuário. Sendo o programa em análise uma política de crédito, e a taxas inferiores às de mercado, ele acaba por se tornar uma fonte considerável de liquidez para os municípios da região. A consequência mais imediata é a maior dinamização da economia do Oeste do Paraná.

Vale notar que isto ocorreu pois, o agricultor familiar normalmente utiliza apenas a mão de obra familiar para suas atividades. Sendo assim, ele consegue reduzir boa parte dos custos relacionados ao custeio de suas atividades sobrando recursos para compra de produtos para sua subsistência. Ressalta-se ainda que isto só ocorre a medida que o agricultor familiar, através do PRONAF investimento, consegue adquirir máquinas e equipamentos que outrora eram alugados de grandes produtores. 
Em relação ao PIB da Indústria nota-se também que, parte desta significativa influência do volume de créditos do programa é proporcionada pela possibilidade de aquisição (PRONAF Investimento), de máquinas e equipamentos necessárias em suas propriedades. Vale enfatizar que não estão incluídos equipamentos importados ou fabricados em outras regiões do país e sim equipamentos fabricados na região, tais como: irrigadores automáticos; bebedouros e comedouro para aviários; sistema de ventilação; entre outros.

Estes resultados indicam que o PRONAF ao longo do período em análise, e possivelmente ao longo de toda sua existência, vem proporcionando uma maior dinâmica nas atividades tanto agrícolas quanto comerciais na região. Conforme apontou Guilhoto et al. (2007) o PRONAF além de possuir importante contribuição para a geração de riquezas no país é responsável por uma parcela bem significativa de todo o produto agropecuário brasileiro.

Ao encontro destes resultados há de se destacar que, de acordo com Castro, Resende e Pires (2014), os agricultores familiares da região Sul do Brasil possuem uma maior integração aos mercados e uma melhor estrutura de divulgação e operacionalização do programa efetuado pelas assistências técnicas. Da mesma forma, outro fator de destaque é a existência de uma rede bancária bem distribuída em relação às demais regiões do país.

\section{Efeitos do Pronaf sobre a geração de emprego e renda}

Esta subseção analisa a contribuição do PRONAF para Geração de Emprego e Renda no período de 2000 a 2012, na região Oeste do Paraná. Levando em consideração a ainda forte relação de informalidade no mercado de trabalho, principalmente no meio rural, há certa dificuldade em analisar os efeitos do programa sobre estas variáveis. Segundo Mattei (2005), especialistas no assunto, tem convencionalmente analisado apenas a dinâmica da produção do setor e a partir daí estimado alguns índices de desempenho do emprego agrícola.

No presente artigo, foi possível fazer algumas considerações sobre 0 comportamento do trabalho e da renda. Cabe destacar que os dados utilizados 
consideram toda a população dos municípios e não apenas a do meio rural. A análise ocorreu desta maneira por não haver dados setoriais disponíveis para estas variáveis.

Apesar das limitações elencadas, o fato de a análise ocorrer utilizando a geração de trabalho e renda de toda a população pode ser encarada como uma vantagem pois, apesar de o PRONAF ser uma política direcionada principalmente ao setor primário, ele proporciona crescimento também nos outros dois setores da economia: indústria; e serviços. Somente com esta observação pode se dizer que uma parte dos serviços gerados na economia como um todo é sim influenciada pelo volume de recursos do programa.

A Tabela 05 apresenta os coeficientes estimados para as variáveis dependentes, Renda Média e Geração de Empregos. Segundo teste de Hausman, o modelo de EA se adequou melhor na análise da Renda Média, enquanto que o modelo de EF se sobressaiu na análise da Geração de Empregos.

\begin{tabular}{|c|c|c|c|}
\hline Variáveis Explicativas & $\begin{array}{c}\text { MQOs } \\
\text { Empilhados }\end{array}$ & $\begin{array}{c}\text { Painel de } \\
\text { Efeitos Fixos }\end{array}$ & $\begin{array}{c}\text { Painel de } \\
\text { Efeitos Variáveis }\end{array}$ \\
\hline \multirow[b]{2}{*}{ Tx. Cresc. Créditos do PRONAF } & \multicolumn{3}{|c|}{ Variável Dependente: Renda Média Populacão } \\
\hline & $\begin{array}{r}0,0075^{\star \star \star} \\
(10,55)\end{array}$ & $\begin{array}{r}0,0077^{* * *} \\
(10,28)\end{array}$ & $\begin{array}{r}0,0075^{\star \star \star} \\
(10,56)\end{array}$ \\
\hline \multirow{2}{*}{$\begin{array}{l}\mathrm{R}^{2} \text { Ajustado } \\
\text { Teste Hausman }\end{array}$} & \multirow[t]{2}{*}{0,7483} & 0,7591 & 0,7483 \\
\hline & & \multicolumn{2}{|c|}{$8,55[0,1282]$} \\
\hline \multirow[b]{2}{*}{ Tx. Cresc. Créditos do PRONAF } & \multicolumn{3}{|c|}{ Variável Dependente: Geração Média de Empregos } \\
\hline & $0,4979^{\star * *}$ & $0,4839^{* * *}$ & $0,4979^{* \star *}$ \\
\hline \multirow{2}{*}{$\begin{array}{l}\mathrm{R}^{2} \text { Ajustado } \\
\text { Teste Hausman }\end{array}$} & $\begin{array}{l}(18,10) \\
0,7831\end{array}$ & $\begin{array}{l}(17,07) \\
0,7943\end{array}$ & $\begin{array}{l}(18,41) \\
0,7831\end{array}$ \\
\hline & & \multicolumn{2}{|c|}{$28,88[0,0000]$} \\
\hline Observações & 600 & 600 & 600 \\
\hline
\end{tabular}

Fonte: Elaboração dos autores.

( ) = T-Statistic, [ ] = P-valor.

${ }^{\star \star \star}$ Significativo a $1 \%$; ${ }^{* *}$ Significativo a $5 \% ;{ }^{*}$ Significativo a $10 \%$.

O coeficiente estimado pelo modelo de EA para a Renda Média foi de 0,0075, com significância de 1\%. Entende-se que um aumento de 10 p.p. na taxa de crescimento do volume de créditos do PRONAF acarreta em um acréscimo de 0,07\% no crescimento anual da Renda Média da população em geral.

De acordo com Mattei et al. (2007) pode-se interpretar que, ao permitir aos seus beneficiários a aquisição de insumos tanto para aumento de área como para 
incorporação de tecnologias, o programa tem influência direta na elevação da renda média do agricultor.

Em relação à geração média de empregos o coeficiente estimado pelo modelo de EF foi de 0,4839, com 1\% de significância. Um acréscimo de 10 p.p. na taxa de crescimento do volume de créditos do PRONAF espera-se que ocorra um crescimento de 4,84\% no número de empregos formais.

Mattei (2005), ao analisar o comportamento dos 100 municípios brasileiros que mais captaram crédito pelo PRONAF, apresentou algumas considerações sobre o mercado de trabalho. Para o autor, assim como na presente pesquisa, o aumento no volume de créditos do programa cria um ambiente favorável a criação de postos de trabalho.

Os resultados obtidos nesta subseção estão de acordo com os encontrados também por Silva (2008). Segundo autor o PRONAF, enquanto uma política social, pode resultar em um relativo aquecimento da economia de pequenos municípios. $O$ que aponta para uma expansão na renda e na demanda por força de trabalho.

\section{Efeitos do Pronaf sobre a geração de receita tributária}

Esta subseção apresenta a contribuição do PRONAF para a geração de receita tributária. Para tanto, dividiu-se a análise em duas partes: a primeira regressão buscou identificar a influência da taxa de crescimento do PRONAF sobre a Geração Média de Impostos Municipais; em um segundo momento buscou-se identificar a contribuição do PRONAF para a geração de ICMS em termos de seus repasses aos municípios da região Oeste do Paraná.

A Tabela 06 apresenta os coeficientes estimados para as variáveis dependentes, Geração Média de Impostos Municipais e Geração de ICMS, bem como para as variáveis de controle. Segundo teste de Hausman, o modelo de EF se sobressaiu na presente análise.

Tabela 06 - Efeitos do PRONAF sobre a geração de receita tributária - região Oeste do Paraná

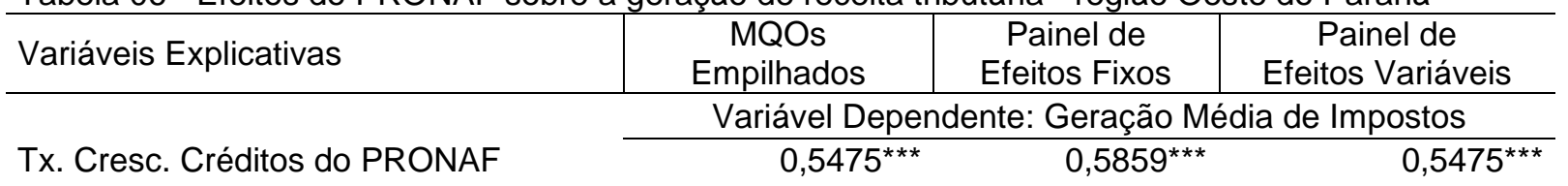




\begin{tabular}{|c|c|c|c|}
\hline $\mathrm{R}^{2}$ Ajustado & $\begin{array}{l}(18,17) \\
0,7574\end{array}$ & $\begin{array}{l}(18,87) \\
0,7700\end{array}$ & $\begin{array}{r}(18,49) \\
0,7574 \\
\end{array}$ \\
\hline Teste Hausman & \multicolumn{3}{|c|}{$28,10 \quad[0,0000]$} \\
\hline & \multicolumn{3}{|c|}{ Variável Dependente: Geração Média de ICMS } \\
\hline Tx. Cresc. Créditos do PRONAF & $0,4724^{\star * *}$ & $0,5032^{\star * *}$ & $0,4724^{* * *}$ \\
\hline $\mathrm{R}^{2}$ Ajustado & $\begin{array}{l}(26,03) \\
0,8270\end{array}$ & $\begin{array}{r}(27,31) \\
0,8401\end{array}$ & $\begin{array}{l}(26,82) \\
0,8270\end{array}$ \\
\hline Teste Hausman & \multicolumn{3}{|c|}{$43,49 \quad[0,0000]$} \\
\hline Observações & 600 & 600 & 600 \\
\hline
\end{tabular}

Os coeficientes estimados para as variáveis de interesse apontaram relação diretamente proporcional e significativa a $1 \%$, tanto em relação à geração de ICMS quanto à geração de impostos municipais. Um acréscimo de 10 p.p. na taxa de crescimento anual do volume de créditos do PRONAF acarreta um aumento de 5,85\% na geração de impostos municipais, e aumento de 5,03 \% na geração de ICMS, segundo modelo de EF. Apesar de utilizar um modelo diferente, Silva (2008) encontrou resultados bem próximos para os municípios do Território Médio Jequitinhonha em Minas Gerais.

Estes resultados reforçam a importância do programa para as administrações municipais. A atuação das prefeituras no sentido de melhorar a estrutura de operacionalização do programa em conjunto com os sindicatos rurais, os agentes financeiros e as entidades de assistência técnica e extensão rural (ATERs) pode ter resultados significativos nas contas municipais. Mattei et al. (2007) salienta que uma maior alocação de recursos no âmbito do programa estimula de forma efetiva o setor produtivo, que por sua vez passa a contribuir mais, elevando a arrecadação de tributos municipais.

Os resultados encontrados nesta subseção expressão novamente a importância do PRONAF para os municípios da região Oeste do Paraná. Os coeficientes encontrados foram positivos e significativos tanto em relação à geração de ICMS quanto em relação à geração de impostos municipais. 


\section{Considerações Finais}

A presente pesquisa objetivou analisar os efeitos do volume de créditos do PRONAF, em relação a importantes variáveis econômicas da região Oeste do Paraná. Em relação a evolução dos créditos do PRONAF, verificou-se durante o período em análise, um crescimento médio de $17,2 \%$ ao ano na região Oeste, enquanto o estado cresceu apenas $13,8 \%$. O mesmo ocorreu com o número de contratos, cerca de $3,6 \%$ ao ano na região e 1,8\% no estado.

Foram encontrados resultados positivos e significativos para todas as variáveis explicativas regredidas contra o volume de créditos do PRONAF. Desta forma, a análise permitiu afirmar concretamente que o programa está cumprindo com seus pressupostos, quais sejam: fortalecer a agricultura familiar, contribuir para gerar emprego e renda nas áreas rurais e urbanas e melhorar a qualidade de vida dos produtores familiares. Com os resultados encontrados notou-se que, em termos gerais, políticas públicas direcionadas para o desenvolvimento rural são capazes de trazer impactos positivos para economia dos municípios.

Apesar de observarmos diferentes proporções nos três modelos, todos apresentaram impactos positivos da taxa de crescimento do PRONAF sobre as variáveis de interesse. Ficou comprovada a existência de uma relação positiva entre o volume de créditos do programa e o crescimento econômico da região estudada.

Os resultados referentes aos efeitos do volume de créditos do PRONAF em relação ao PIB Per Capita e aos três setores em separado dos municípios observaram-se, com alto grau de significância, que o programa os afeta positivamente. Notou-se que, apesar de o PRONAF ser uma política setorial direcionada à agropecuária (setor primário), ela fornece insumos e transfere renda tanto para o setor de serviços quanto para o setor industrial.

Algo interessante a se destacar é que os efeitos sobre os setores de serviços e indústria foram ainda maiores que os efeitos sobre o próprio setor agropecuário. Este fato está diretamente relacionado á natureza da política em análise (O Crédito). Tendo em vista que os volumes de crédito do PRONAF são uma fonte considerável de liquidez para esses municípios, a consequência mais imediata é o efeito de encadeamento, dinamizando a economia. O que se observou é que além de ter 
recursos para custear suas atividades, com taxas abaixo das de mercado, o agricultor familiar também direciona parte destes recursos para sua própria subsistência.

A análise quanto à geração de emprego e renda também encontrou coeficientes positivos significativos. Vale destacar que devido à disponibilidade de dados, as séries utilizadas se referem a toda à população da região. No entanto, isto pode ser encarado como uma vantagem, pois conforme verificado o PRONAF não afeta apenas o setor agropecuário e sim toda a economia dos municípios da região.

$\mathrm{Na}$ medida em que os setores de indústria e serviços são os que, atualmente, geram maior número de empregos formais, o fato de o volume de créditos também os influenciar destaca o caráter social do programa. Ao propiciar maior influência nos setores secundário e terciário, o PRONAF causa elevação tanto no número de empregos formais quanto na renda média da população.

A análise dos efeitos do PRONAF sobre a arrecadação tributária municipal da região Oeste do Paraná por si só justifica e indica que é necessário um maior interesse dos governos municipais no sentido de incentivar e criar mecanismos para uma maior operacionalização desta política. Com mais recursos em caixa, as administrações municipais têm a possibilidade de, além de equilibrar suas contas, fazer novos investimentos.

Vale notar que os resultados encontrados em todas as variáveis são em grande parte fruto da interação entre as organizações envolvidas no programa. Entre eles: os Sindicatos de Trabalhadores Rurais, as Prefeituras Municipais, as entidades de assistência técnica e os agentes financeiros. As ações destas organizações foram e continuam sendo de suma importância para expansão do programa na região Oeste do Paraná.

Acima de tudo, para melhoria nos resultados encontrados há necessidade de um ambiente institucional favorável e bem estabelecido a nível municipal. Desta forma, as análises de políticas públicas, como a que motivou a presente pesquisa, são um instrumento relevante para o aperfeiçoamento das ações do poder público.

Um melhor entendimento sobre o funcionamento e sobre os efeitos que as políticas causam nas economias locais pode propiciar e motivar melhoras na alocação de recursos públicos, o que por consequência resulta em efeitos significativos na 
produção, no aumento da renda e na melhoria na qualidade de vida de toda a população.

O instrumental econométrico utilizado para esta pesquisa, pode, em estudos futuros, ser estendido para regiões com características distintas do Oeste do Paraná. Sendo o Brasil um país de dimensões continentais pode ser que em outras regiões não se obtenha os mesmos resultados.

Da mesma forma, como extensão da presente pesquisa, é possível verificar os efeitos do programa em relação aos diferentes grupos de beneficiários, atualmente classificados em “A”, “A/C”, "B”, e “Agricultor Familiar” (Quadro 02).

Outra sugestão para complementar da presenta análise, pode ser viável após a realização do Censo Agropecuário, estimado para ocorrer em 2017. Visto que há apenas um Censo que contempla dados sobre a agricultura familiar após 2018 será possível realizar uma análise comparativa entre os dados dos anos de 2006 e 2017.

\section{REFERÊNCIAS}

ABRAMOVAY, R. (1997). De volta para o futuro: mudanças recentes na agricultura familiar. In: Io Seminário do Programa de Pesquisa em Agricultura Familiar da EMBRAPA. Anais ...., pp. p. 17-27.

ABRAMOVAY, R. (2006). Agricultura Familiar e Reforma Agrária. In. Estudo da Dimensão Territorial do PPA.

ABRAMOVAY, R. (2009). O futuro das regiões rurais (2 $2^{-}$Ed ed.). Porto Alegre, RS: UFRGS. ABRAMOVAY, R., \& VEIGA, J. E. (1999). Novas instituições para o desenvolvimento rural: o caso do Programa Nacional de Fortalecimento da Agricultura Familiar (PRONAF). Brasília, DF: IPEA.

ALEIXO, C. E., OLIVEIRA, L. A., REIS, A. P., MUNIZ, K. T., \& LIMA, P. V. (2007). Impactos do PRONAF nos indicadores de qualidade de vida de seus beneficiados no assentamento Santana-CE. In: Simpósio Brasileiro de sistema de produção, 7., 2007. Anais . ., p. 11 p.

ARAUJO, P. F. (2011). Política de crédito rural: reflexões sobre a experiência brasileira. Brasília, DF.

BACEN. (2015). Banco Central do Brasil. 
BACHA, C. J. (2012). Economia e política agrícola no Brasil (2ª ed.). São Paulo, SP, SP, Brasil: Atlas.

BARBOSA, G. J., \& COUTO, E. P. (2008). Evolução das políticas agrícolas e o incentivo à iniciativa privada na agricultura brasileira. XLVI Congresso da Sociedade Brasileira de Economia, Administração e Sociologia Rural (SOBER), Rio Branco, AC.

BARROS, G. S. (2010). Política agrícola no Brasil: subsídios e investimentos. In: J. G. GASQUES, J. E. FILHO, \& Z. NAVARRO, A agricultura brasileira: desempenho, desafios e perspectivas (p. 298). Brasília, DF: IPEA.

BARROS, R. P., \& LIMA, L. (2012). Avaliação de impacto de programas sociais. In: N. Menezes Filho, Avaliação econômica de projetos sociais (1ª Ed. ed., pp. 13-29). São Paulo, SP: Dinâmica Gráfica e Editora.

BELUSSO, D., \& SERRA, E. (2006). Caracterização Sócio-Espacial da agricultura no Oeste Paranaense: Um estudo de caso em Palotina-PR. Agrária, 4, 20-39.

BITTENCOURT, G. A. (2003). Abrindo a caixa preta: o financiamento da agricultura familiar no Brasil. 2003, 243 f. Dissertação (Mestrado em Economia) - Instituto de Economia da Universidade Estadual de Campinas - UNICAMP, Campinas, SP.

BITTENCOURT, G. A., \& ABRAMOVAY, R. (2001). Inovações institucionais no financiamento à agricultura familiar: o Sistema Cresol. Economia Ensaios.

BRASIL. (1996). Decreto no 1.946, de 28 de junho de 1996. Cria o Programa Nacional de Fortalecimento da Agricultura Familiar (PRONAF).

BRASIL. (2006). Lei no 11.326, de 24 de julho de 2006. Estabelece as diretrizes para a formulação da Política Nacional de Agricultura Familiar e Empreendimentos Familiares Rurais. 2006.

BUAINAIN, A. M. (2006). Agricultura familiar, agroecologica e desenvolvimento sustentável: questões para debate (1a Ed. ed.). Brasília, DF: Instituto Interamericano de Cooperação para a Agricultura - IICA.

BUAINAIN, A. M. (2007). Modelo e principais instrumentos de regulação setorial: uma nota didática. In: P. Ramos, Dimensões do agronegócio brasileiro: políticas, instituições e perspectivas (pp. 53-102). Brasilia, DF: MDA.

BUAINAIN, A. M., \& SOUZA FILHO, H. M. (1998). PROCERA: impactos produtivos e capacidade de pagamento. Projeto FAO/INCRA - Relatório Final, Campinas, SP.

BUENO, L. R. (2008). Avaliação Socioeconômica do PRONAF no estado do Paraná. 2008, 99 f. Dissertação (Mestrado em Economia) - Programa de Pós-Graduação em Economia da Universidade Federal de Santa Catarina (PPGE), Florianópolis, SC. 
CARNEIRO, M. J. (1997). Política pública e agricultura familiar: uma leitura do PRONAF. Estudos Sociedade e Agricultura, 8, Rio de Janeiro, RJ.

CARVALHO, F. J. (2001). Política agrária do governo FHC: desenvolvimento rural e nova reforma agrária. In: S. P. LEITE, Políticas públicas e agricultura no Brasil (p. 250). Porto Alegre, RS: Ed. UFRGS.

CASTRO, C. N., RESENDE, G. M., \& PIRES, M. J. (2014). Avaliação dos impactos regionais do Programa Nacional da Agricultura Familiar (PRONAF). Rio de Janeiro, RJ: IPEA.

CONCEIÇÃO, J. C. (2003). Política de preços mínimos e a questão do abastecimento alimentar. Brasília, DF: IPEA.

COPETTI, L. D. (2008). Fatores que dificultam o acesso dos agricultores familiares às políticas de crédito rural: O caso do PRONAF-CRÉDITO no município de Alegria-RS. 2008, 206 f. Dissertação (Mestrado Desenvolvimento Rural) - Universidade Federal do Rio Grande do Sul - UFRS, Porto Alegre, RS.

CORRÊA, V. P., \& SILVA, F. F. (2004). O novo desafio do financiamento agrícola e as dificuldades para os produtores não integrados. In: Congresso da Sociedade Brasileira de Economia e Sociologia Rural, 42., 2004. Anais ..., p. 25 p.

Da Silva, J. F. (1999). O novo rural brasileiro. Universidade Estadual de Campinas (UNICAMP), Campinas, SP.

DANTAS, I., \& PINTO, J. R. (2006). Relatório PRONAF: resultados da etapa Paraná. Instituto Brasileiro de Análises Sociais e Econômicas (Ibase), Rio de Janeiro/RJ.

DOMINGUES, A. P. (2007). Crédito PRONAF: Conquista, afirmação e reconhecimento. $O$ processo de formulação de uma política pública. 2007, 171 f. Dissertação (Mestrado Administração Pública) - Programa de Pós-Graduação em Administração Pública da Fundação Getulio Vargas (FGV), Rio de Janeiro, RJ.

DURLAUF, S. N., JOHNSON, P. A., \& TEMPLE, J. R. (2005). Growth Econometrics. In: P. AGHION, \& S. DURLAUF, Handbook of economic growth. England: Elsevier.

FAO/INCRA. (1994). Diretrizes de política agrária e desenvolvimento sustentável para a pequena produção familiar. FAO/INCRA, Brasília, DF.

FAO/INCRA. (2000). Novo retrato da Agricultura Familiar: O Brasil redescoberto.

FAO/INCRA, Brasília, DF.

FREITAS, C. A., \& BACHA, C. J. (2002). Análise do crescimento desigual do setor agropecuário brasileiro em termos de produtos e estados, período de 1970 a 1996. XL Congresso da Sociedade Brasileira de Economia, Administração e Sociologia Rural (SOBER), Passo Fundo, RS. 
GASQUES, J. G., \& VILLA VERDE, C. M. (2003). Gastos públicos na agricultura, evolução e mudanças. Brasília, DF: IPEA.

GASQUES, J. G., FREITAS, R. E., BASTOS, E. T., SILVA, H. D., \& SILVA, A. R. (2005). Agricultura familiar - PRONAF: análise de alguns indicadores. In Congresso da Sociedade Brasileira de Economia e Sociologia Rural, 43, 2005. Anais. .., p. 21 p.

GASQUES, J. G., REZENDE, G. C., VILLA VERDE, C. M., SALERNO, M. S., CONCEIÇÃO, J. C., \& CARVALHO, J. C. (2004). Desempenho e crescimento do agronegócio no Brasil. Brasília, DF: IPEA.

GOMES, S. C. (2007). Análise econométrica da produtividade total dos fatores na amazônia legal, 1990-2004. 2007, 262 f. Tese (Doutorado em Economia Aplicada) - Programa de PósGraduação em Economia Aplicada da Universidade Federal de Viçosa (UFV), Viçosa, MG.

GREENE, W. H. (2002). Econometric Analysis. New Jersey: Prentice Hall/Upper Saddle River.

GUANZIROLI, C. E. (2006). PRONAF dez anos depois: resultados e prespectivas para o desenvolvimento rural. In: Congresso da Sociedade Brasileira de Economia e Sociologia Rural, 44. Anais ..., p. 29 p.

GUANZIROLI, C. E. (2007). PRONAF dez anos depois: resultados e perspectivas para o desenvolvimento rural. Economia e sociologia rural.

GUANZIROLI, C. E., ROMEIRO, A., BUAINAIN, A. M., DI SABBATO, A., \& BITTENCOURT, G. (2001). Agricultura Familiar e Reforma Agrária no Século XXI. Rio de Janeiro, RJ: Garamond.

GUANZIROLI, C. H., BUAINAIN, A. M., \& DI SABBATO, A. (2012). Dez anos de evolução da agricultura familiar no Brasil: (1996 e 2006). Revista de Economia e Sociologia Rural (RESR), Vol. 50, n.2, p. 351-370.

GUILHOTO, J. J., ICHIHARA, S. M., SILVEIRA, F. G., DINIZ, B. P., AZZONI, C. R., \& MOREIRA, G. R. (2007). A importância da Agricultura Familiar no Brasil e em seus estados. NEAD - Núcleo de Estudos Agrários e Desenvolvimento Rural - MDA, Brasília, DF.

GUJARATI, D. N., \& PORTER, D. C. (2011). Econometria Básica (5ª Ed. ed.). (D. Durante, M. Rosemberg, \& M. L. Rosa, Trads.) Porto Alegre, RS: AMGH Editora Ltda.

HAMPF, A. C. (2013). Avaliação do impacto do PRONAF sobre a agricultura familiar no município de Bonito, estado de Pernambuco, mediante uso do Proepsity Score Matching. 2013, 128 f. Dissertação (Mestrado em Políticas Públicas e Desenvolvimento Rural Sustentável) - Programa de Pós-Graduação em Administração e Desenvolvimento Rural da Universidade Federal Rural de Pernambuco., Recife, PE.

IAP. (2015). Instituto Ambiental do Parana - IAP. Acesso em 21 de Novembro de 2015, disponível em http://www.iap.pr.gov.br/ 
IM, K. S., PESARAN, M. H., \& SHIN, Y. (1997). Testing for Unit Roots Heterogeneous Panels. Working Paper.

IPARDES. (2008). Os Vários Paranás. Oeste Paranaense: o 3ํㅗspaço. Especificidades e Diversidades/Instituto Paranaense de Desenvolvimento Econômico e Social, Curitiba, PR.

ISLAM, N. (1995). Growth Empirics: A panel data approach. The Quarterly Journal of Economics, 110(4), 127-170.

LEVIN, A., \& LIN, C.-f. (1992). Unit Root Tests in Panel Data: Asymptotic and Finite-Sample Properties. Discussion Paper, 92-23.

LEVIN, A., LIN, C.-F., \& CHU, C.-S. J. (2002). Unit root tests in panel data:asymptotic and fnite-sample properties. Journal of Econometrics(108), 1-24.

LEVINE, R. (2005). Finance And Growth: Theory And Evidence. In: P. AGHION, \& S. N. DURLAUF, Handbook of economic growth (1ํㅡㄹ ed., pp. 865-934). Elsevier.

MAGALHÃES, A. M. (2005). The family farm program in Brasil: the case of Parana. In XVII Congresso SOBER. Anais ...

MATTEI, L. (2005). Impactos do Pronaf: análise de indicadores. Brasília, DF: MDA, Núcleo de Estudos Agrários e Desenvolvimento Rural.

MATTEI, L., WAQUIL, P., SCHNEIDER, S., CONTERATO, M., RADOMSKY, G., NAMIZADI, G., et al. (2007). Uma análise dos impactos do PRONAF sobre as economias locais nas regiões Nordeste, Sudeste e Norte do Brasil. XLV Congresso da SOBER, Londrina, PR.

PIRES, M. J. (2009). Implicações do processo de modernização na estrutura e nas atividades agropecuárias na região Centro-Sul do estado de Goiás. 47º Congresso da Sociedade Brasileira de Economia, administração e Sociologia Rural (SOBER), Porto Alegre, RS.

PIRES, M. J. (2013). Contradições em um processo: um estudo da estrutura e evolução do PRONAF de 2000 a 2010. Brasília, DF: IPEA.

REZENDE, G. C. (2000). Política de preços mínimos na década de 90: dos velhos aos novos instrumentos. Rio de Janeiro, RJ: IPEA.

SANTOS, G. R., SOUZA, A. G., \& ALVARENGA, G. (2013). Seguro agrícola no Brasil e o desenvolvimento do programa de subvenção ao prêmio. Brasília, DF: IPEA.

SCHMITZ, H., \& MOTA, D. M. (Janeiro a Dezembro de 2007). Agricultura familiar: elementos teóricos e empíricos. Agrotrópica, Volume 19, p. 80 p.

SCHNEIDER, S. (2003). A pluriatividade na agricultura familiar. Porto Alegre, RS: UFRGS Editora. 
SILVA, F. F. (2006). Distribuição de crédito para agricultura familiar: um estudo do PRONAF a partir de um indicador de desenvolvimento rural. 2006, 250 f. Dissertação (Mestrado em Economia) - Programa de Pós-Graduação em Economia da Universidade Federal de Uberlândia (UFU), Uberlândia, MG.

SILVA, S. P. (2008). Políticas públicas e agricultura familiar: uma abordagem territorial do PRONAF no Médio Jequitinhonha. 2008, 169 f. Dissertação (Mestrado em Economia) Programa de Pós-Graduação em Economia da Universidade Federal de Viçosa (UFV), Viçosa, MG.

SILVA, S. P. (2015). Agricultura familiar e suas múltiplas interaçoes com o território: uma análise de suas características multifuncionais e pluriativas. Brasília, DF: IPEA.

STADUTO, J. A. (1995). Os Mercados de Opções Agrícolas: Uma alternativa de financiamento para a agricultura. 1995,133f. Dissertação (Mestrado) Universidade Federal de Viçosa (UFV), Viçosa, MG.

TEMPLE, J. (1999). The New Growth Evidence. Journal of Economic Literature, 37, 112156.

VERBEEK, M. (2004). A Guide to Modern Econometrics (2ª Ed ed.). (M. VERBEEK, Ed.) England: John Wiley \& Sons, Ltd.

WANDERLEY, M. d. (1996). Raízes históricas do campesinato brasileiro. XX Encontro anual da APOCS. GR 17. Processos sociais agrários, Caxambu, MG.

WOOLDRIDGE, J. M. (2010). Econometric Analysis Of Cross Section And Panel Data (2 ${ }^{\underline{a}}$ Ed. ed.). LONDON, EN: The MIT Press.

\section{NOTAS DE AUTOR}

\section{CONTRIBUIÇÃO DE AUTORIA}

Os papéis descrevem a contribuição específica de cada colaborador para a produção acadêmica inserir os dados dos autores conforme exemplo, excluindo o que não for aplicável.

Fagner Mendonça Avelar - Concepção. Coleta de dados, Análise de dados, Elaboração do manuscrito, revisão e aprovação da versão final do trabalho

Cristiano Stamm - Concepção e elaboração do manuscrito. Participação ativa da discussão dos resultados;

Revisão e aprovação da versão final do trabalho.

\section{FINANCIAMENTO}

Não se aplica.

CONSENTIMENTO DE USO DE IMAGEM

Não se Aplica.

APROVAÇÃO DE COMITÊ DE ÉTICA EM PESQUISA

Não se Aplica

CONFLITO DE INTERESSES

Não há conflitos. 
LICENÇA DE USO

Este artigo está licenciado sob a Licença Creative Commons CC-BY. Com essa licença você pode compartilhar, adaptar, criar para qualquer fim, desde que atribua a autoria da obra.

HISTÓRICO

Recebido em: 21-07-2017

Aprovado em: 24-04-2019 